\title{
Powder Characterization of Calcium Phosphate/Collagen for Bone Implant Application
}

\author{
Nor Azimah Mustaffa, , ,Sharifah Adzila ${ }^{1, \text { b }}$, Nanthini Kanasan ${ }^{1}$, and Normayati Nordin $^{1}$ \\ ${ }^{1}$ Faculty of Mechanical Engineering, Material and Design Department, Universiti Tun Hussein Onn \\ Malaysia (UTHM)
}

\begin{abstract}
Calcium phosphate $(\mathrm{CaP})$ is a type of bioceramic material that is biocompatible and bioactive. It is usually used for bone implant application but it lacks mechanical strength. Therefore, sodium alginate (SA), a natural polymer, is combined with $\mathrm{CaP}$ to improve its properties of the $\mathrm{CaP}$ via precipitation method. The powder formed is then characterized by using FESEM, EDX, FTIR and DTA. Based on the FESEM result, it was confirmed that the SA particles were well embedded and homogeneously dispersed throughout the $\mathrm{CaP}$ matrix whereas the $\mathrm{EDX}$ result showed that the $\mathrm{CaP}$ and $\mathrm{SA}$ are pure and were not contaminated with other materials or substances.The FTIR result showed that the intensity of some peaks $(3100-3600 \mathrm{~cm}-1$ and $1585-1625 \mathrm{~cm}-1)$ increased due to the addition of SA but for some peaks the addition of SA leads to a decrease in intensity $(1650-1300 \mathrm{~cm}-1$ and $1190-976 \mathrm{~cm}-1)$. This proves that the addition of $\mathrm{SA}$ in $\mathrm{CaP}$ influenced the intensity peaks and it was confirmed that chemical bonds were formed between these two substances. Meanwhile, the DTA result showed that $\mathrm{CaP}$ dehydroxylation occurred in the range of $650-13000 \mathrm{C}$ and the thermal degradation of SA happened at 245.80C but the SA thermal degradation temperature improved when it was added to the $\mathrm{CaP}$ matrix.
\end{abstract}

\section{Introduction}

Bones play an important part in the human body as they support body tissue and protect human organs. The human bone also acts as mineral storage (calcium and phosphorus) [1].Bone defectslike fractures, cancer, bone loss (osteoporotic) and other debilitating diseases can influence the function of bones in the human body. 60 to $70 \%$ of bone tissues consist of mineral calcium, phosphate and collagen, while the remaining percentage consists of inorganic elements and water [2]. Similarities between calcium phosphate (CaP) and the mineral content in bone tissue were the reason why calcium phosphate was chosen for this study [3].Calcium phosphate $(\mathrm{CaP})$ has been used for repairing bone defects, dental and bone tissue applications in the human body since 1920 [4].Calcium phosphate (CaP) is

Corresponding author: a) $\underline{\text { meemek90@gmail.com }, \text { b)adzila@uthm.edu.my }}$ 
a type of ceramic material that is biocompatible, non-toxic and resorbable. Furthermore, calcium phosphate $(\mathrm{CaP})$ is a bioactive and osteoconductive material that can promote new bone growth and promote cellular function and expression $[3,5]$. The lack of the calcium phosphate $(\mathrm{CaP})$ makes it limited in the application of artificial bone implant $[3,5,6]$. Due to that, the combination of different materials known as composite material have been introduced to improve the propertiesof calcium phosphate $(\mathrm{CaP})$ [7].

Biocomposites for bone implant application usually consist of a combination of calcium phosphates with polymer materials (collagen, HDPE, PLGA, alginate etc.) or metal (stainless steel, $\mathrm{Ti}, \mathrm{Mg}$ and etc.) to enhance the properties of $\mathrm{CaP}$. In this study, polymer material is used due to the mechanical properties of the polymer that can be tailored for specific applications and easily fabricated into any desired shape. This gives polymers an edge over ceramics materials (CaP) [8]. However, synthetic polymers like PLGA, PLA, PGA among others can inhibit the deformation of cell growth due to their hydrophobic surface whereas some synthetic polymers are harmful to our body system because they go through acidic degradation and invoke a chronic immune response [9].

Sodium alginate (SA) was chosen as it is anatural polymer that is extracted from brown algae and it is hydrophilic, biocompatible and biodegradable.It is usually used in the food and chemical industry but it has recently been developed for living tissue applications in wound healing, drug and protein delivery [10-12]. Sodium alginate (SA) is soluble in water and that possesses rheological properties. Sodium alginate has been used as a thickening or gelling agent, colloidal stabilizer and as a blood expander in the pharmaceutical industry for a long time [13]. A combination of $\mathrm{CaP}$ and $\mathrm{SA}$ was prepared using the precipitation method. Precipitation method is one of the simple methods that can easily be done and used to control the morphology and mean size of the powder [14].

The addition of sodium alginate to hydroxyapatite (HA) showed an increase in intensity at 962 and $471 \mathrm{~cm}^{-1}$ that leads to the growth rate of HA [10]. The alginate did not affect the subsequent modification of the characteristic band of calcium titanium phosphate (CTP) and HA.This showed that both ceramics were maintained in the microsphere [13].A study by Kui Zhou showed that porous HA/SA 3D material was formed afterweight loss occurredthrice at $100^{\circ} \mathrm{C}, 300$ to $400^{\circ} \mathrm{C}$ and $600-1300^{\circ} \mathrm{C}$ respectively. This was confirmed by the DSC-TG graph [15].During the SEM analysis, it was found that the HA particles were homogenously dispersed and well embedded throughout the SA particles $[10,13]$.

Based on the literature, it was showed that HA has been used inthe study of composite materials. However, in previous studies, calcium hydrogen phosphate wasnot widely used in combination with SA to produce composite material. The aim of this study is to explore the effect of calcium hydrogen phosphate in the SA filler as a $\mathrm{CaP} / \mathrm{SA}$ composite with varying weight percentages of SA.

\section{Sample Preparation}

\subsection{CaP/SA sample preparation}

Calcium hydrogen phosphate $\left(\mathrm{CHPO}_{4}\right)$ from Fisher Scientific was used as the matrix material and combined with sodium alginate (SA, R\&M Chemicals) with different weight percentages at $0.5,1.0,3.0,5.0,10$ and $20 \mathrm{wt} \%$ by using the precipitation method. The CaP $(99.5 \mathrm{wt} \%)$ was stirred with distilled water by using a magnetic stirrer at $80^{\circ} \mathrm{C}$ for 2 hours and then the SA $(0.5 \mathrm{wt} \%)$ powder was added while stirring vigorously. The mixture is continuously stirred for another 2 hours until a paste is formed and the paste will be stored at an ambient temperature for 24 hours. Thereafter, the solution will be dried in the oven at $80^{\circ} \mathrm{C}$ for 24 hours and then grounded using a mortar and pestle to form a fine powder. 
The same procedure was used to prepare other composite materials, namely 1.0, 3.0, 5.0, 10 and $20 \mathrm{wt} \%$.

\subsection{Sample morphology and characterization}

The microstructure of the powder was obtained by using field emission scanning electron microscope (FESEM) (JEOL JSM-7600F). The samples need to be prepared before running the FESEM analysis. The sample was coated with gold by using a sputter coater for 45 seconds with 20 -mA current and images of the microstructure were taken.

The Fourier transform infrared spectroscopy (FTIR) (Perkin Elmer Spectrum 100 Machine) was conducted to obtain the characteristic peaks of the chemical bond of the pure $\mathrm{CaP}$ and $\mathrm{CaP} / \mathrm{SA}$ composites. The powder was analyzed by using the Perkin Elmer Spectrum 100 machineat a resolution of $4 \mathrm{~cm}^{-1}$.

\subsection{Thermal analysis}

Differential thermal analysis (DTA) (DTA L62) was conducted to analyze the phase reaction and phase diagram at different temperatures. The sample powder was filled into $1 / 3$ of a crucible and weighed. The crucible was put into the furnace where the temperature and heating rate wereset at $1300{ }^{\circ} \mathrm{C}$ and $10 \mathrm{~min} /{ }^{\circ} \mathrm{C}$ respectively.

\section{Result and Discussion}

\subsection{Field emission scanning electron microscope}

Figure 1 shows the FESEM image for the pure $\mathrm{CaP}$, SA and the $\mathrm{CaP} / \mathrm{SA}$ composite. The structure of the $\mathrm{CaP} / \mathrm{SA}$ particles showed that when there is an increase in the SA content, more flakey structures were formed in the particles caused by the structure of SA particles (Figure 2). All the combinations showed that the SA was identified with CaP because the SA fully covered the CaP surface [10,13].The EDS results (Figure 2) showed that the sodium $(\mathrm{Na})$ peak was identified in the composite and the extensive peak was formed when a higher $w t \%$ of SA added. 

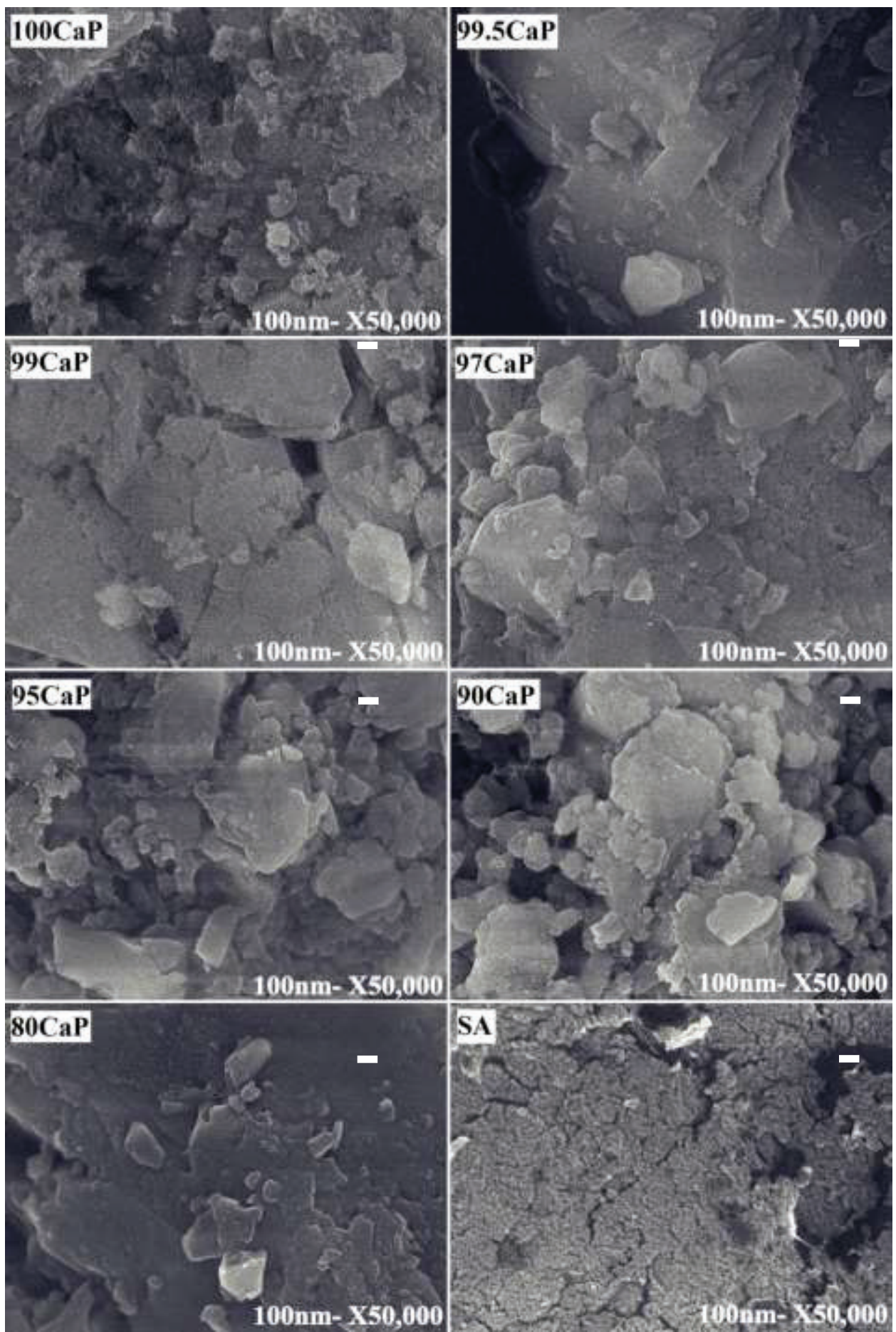

Fig. 1. FESEM image for all compositions of $\mathrm{CaP} / \mathrm{SA}$ in $\mathrm{X} 50,000$ 


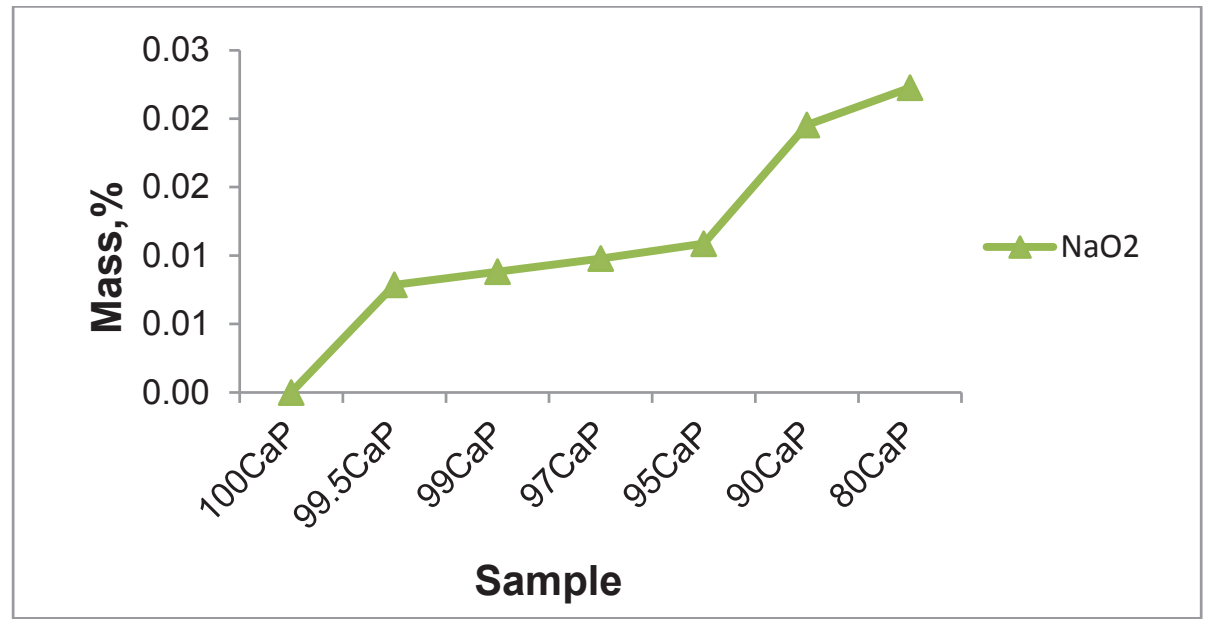

Fig. 2. Mass percentage of the Sodium $\left(\mathrm{NaO}_{2}\right)$ for $\mathrm{CaP} / \mathrm{SA}$ composite

\subsection{Fourier Transform Infra-Red (FTIR)}

FTIR spectra for the composite (CaP/SA), pure SA and $\mathrm{CaP}$ are shown in Figure 3 and Figure 4.The broad peak was detected in pure SA at range $3100-3600 \mathrm{~cm}^{-1}$ due to water $\left(\mathrm{H}_{2} \mathrm{O}\right)$ absorption and stretching mode of surface hydroxyl groups [10,16]. Carboxyl $(\mathrm{C}=\mathrm{O})$ stretching vibration was detected at $1590-1750 \mathrm{~cm}^{-1}$ [16] where the intensity of the peaks increased when there is an increase the $\mathrm{SA}$ content in the $\mathrm{CaP} / \mathrm{SA}$ composite sample and the peak was more extensive for sample $80 \mathrm{CaP}$. The peak that was observed in the region between 1405 to $1456 \mathrm{~cm}^{-1}$ and $1025.4 \mathrm{~cm}^{-1}$ belongs to the carboxyl $-\mathrm{COOH}$ stretching band [16] and C-O stretching vibration [17] respectively where the peaks were detected in pure SA only. The peak $\mathrm{V}_{3}$, hydroxyl stretch carbonate and phosphate were observed between 1300 and $1650 \mathrm{~cm}^{-1}$ [18] 976 and $1190 \mathrm{~cm}^{-1}$ [18,19]respectively, where the highest peaks was observed for sample $99 \mathrm{CaP}$ which contains $1 \mathrm{wt} \%$ of SA but the increasing $\mathrm{wt} \%$ of SA led to a decreasein intensity. The peak for $\mathrm{C} 1-\mathrm{H}$ deformation manunuronic acid residue and hydroxyl stretch phosphate $\mathrm{V}_{4}$ was observed between $878.9-882.4 \mathrm{~cm}^{-1}$ [17] and $520-600 \mathrm{~cm}^{-1}[18,20,21]$ respectively where both of these peaks were observed in sample $97 \mathrm{CaP}$. Based on the results, the addition of the SA influenced the intensity peaks of the composite where the formation of chemical bonds occurred between both materials. 


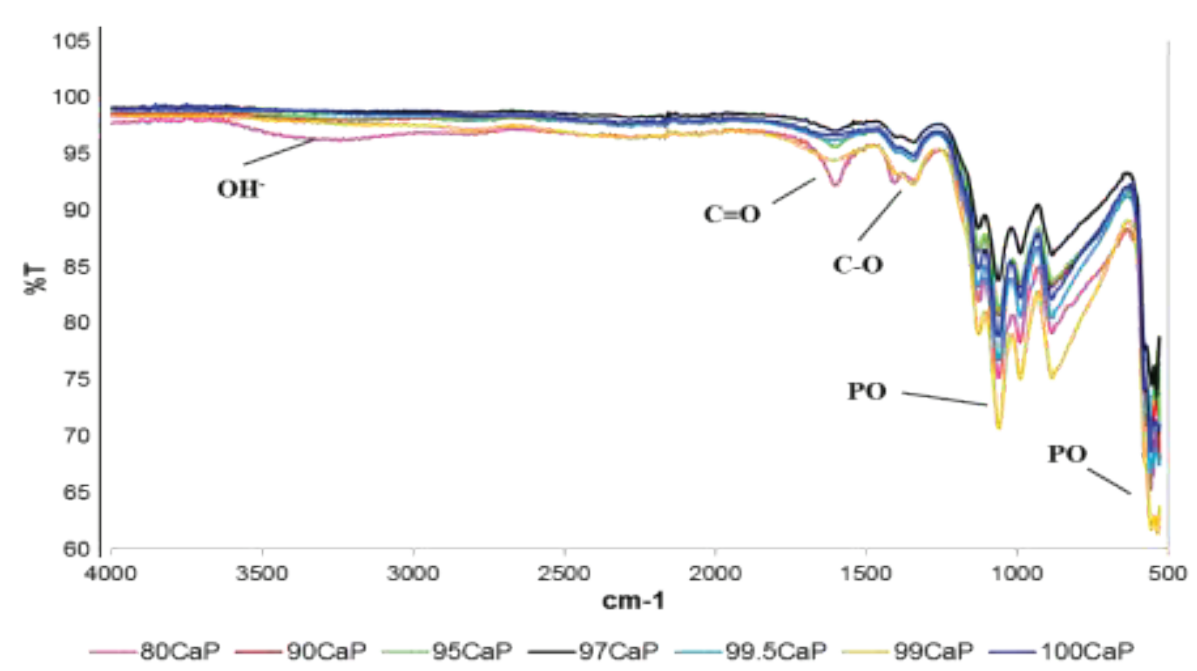

Fig. 3. FTIR result for pure $\mathrm{CaP}$ and $\mathrm{CaP} / \mathrm{SA}$ for all compositions

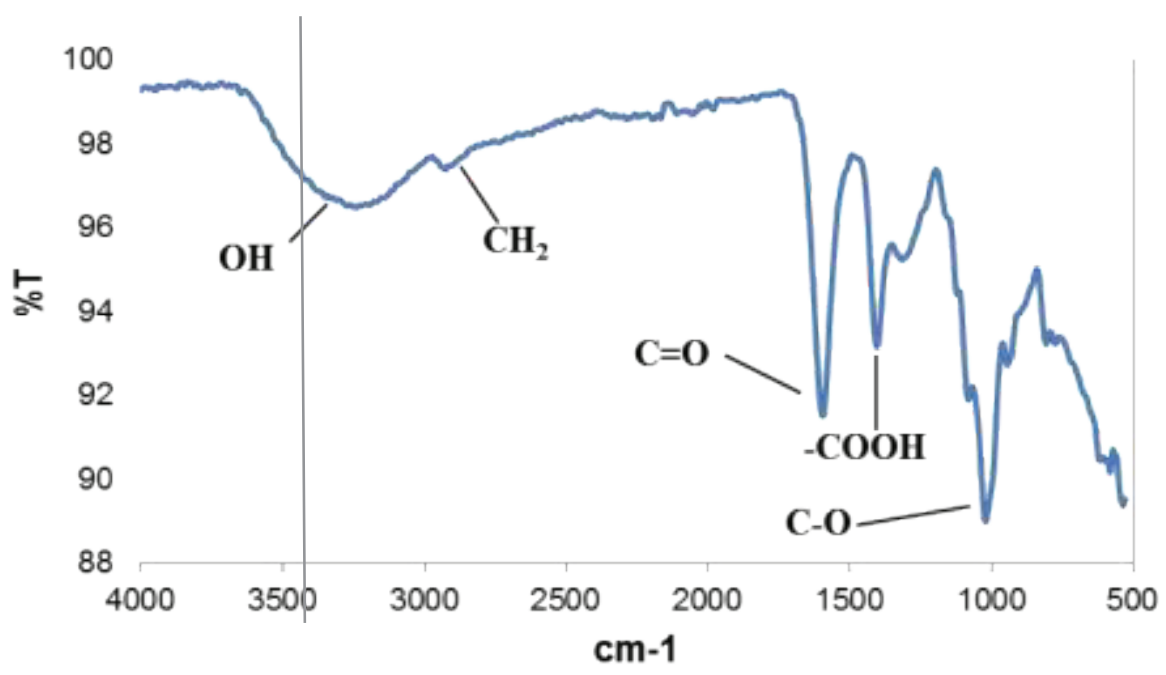

Fig.4. FTIR result for pure SA

\subsection{Differential thermal analysis}

DTA results for pure SA, CaP and CaP/SA composite are shown in Figure 5. Based on the figure, an exothermic peakwas detected between $100^{\circ} \mathrm{C}$ and $70^{\circ} \mathrm{Cand}$ the peak was also observed in pure $\mathrm{SA}$ at $150^{\circ} \mathrm{C}$ where oxidation occurred when the temperature started to increase and causeda change in the crystal structure of the SA as well as the loss of water in the samples $[15,21,22]$. The results showed the temperature approached $150^{\circ} \mathrm{C}$ (SA sample) when the $w t \%$ of SA was increased in the CaP/SA composite. A range between 240 until $360^{\circ} \mathrm{C}$ was observed as endothermic peaks occurred for all samples. A pure SA peak was detected at $245.8^{\circ} \mathrm{C}$ where thermal degradation of intermolecular side chains took place [21]. This also affected the CaP/SA composite where $5 \mathrm{wt} \%$ of SA achieved a higher 
temperature but the temperature decreased when a higher wt $\%$ of SA was added to the CaP. The crystal structure changed and chemical composition reduction was observed in pure $\mathrm{CaP}$ where the endothermic peak was detected at $357.8^{\circ} \mathrm{C}$. The broad exothermic peak was induced at a range of 1100 to $1250^{\circ} \mathrm{C}$ where the highest peak was obtained at $100 \mathrm{CaP}$ and the peak gradually disappears when the wt $\%$ of SA increases. This peak occurred due to the dehydroxylation of $\mathrm{CaP}$ in the range of $650-1300^{\circ} \mathrm{C}$ and the break down reaction of SA [15].

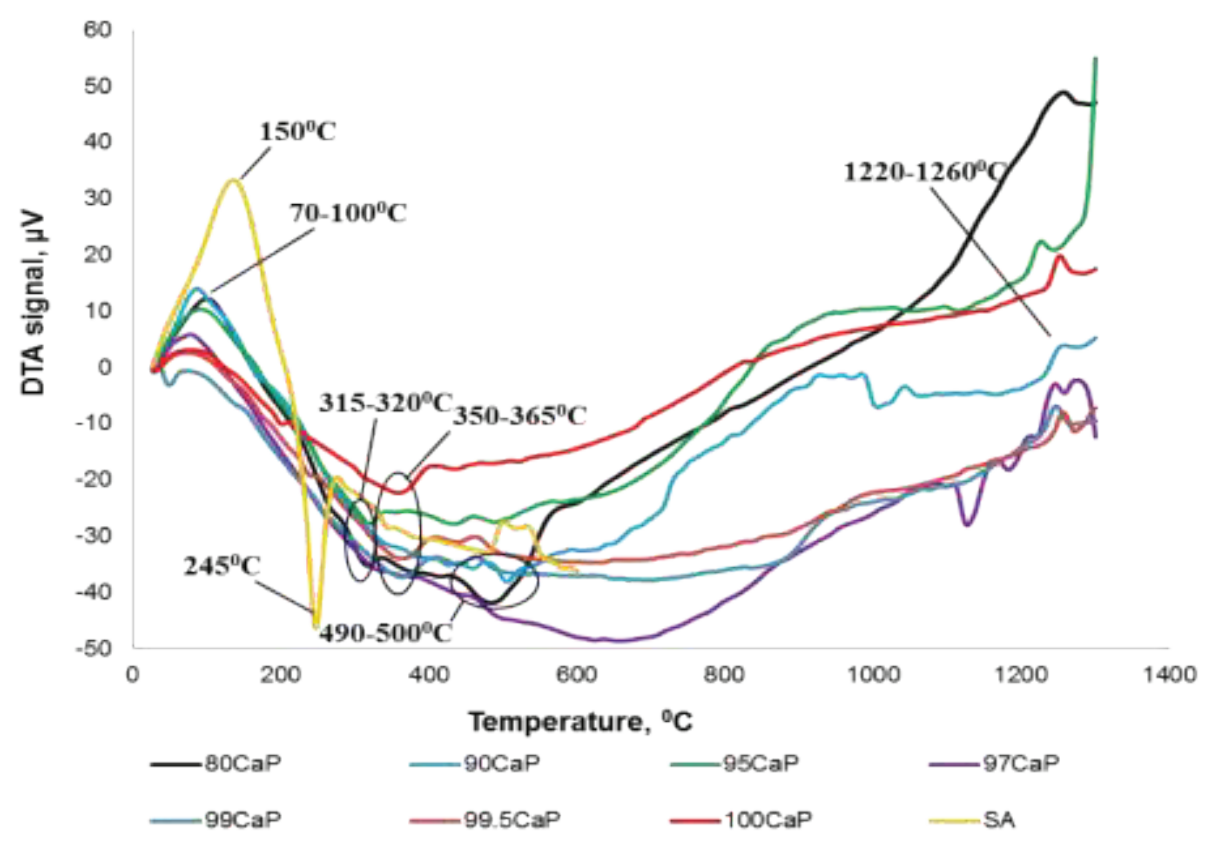

Fig. 5. DTA pattern for the pure $\mathrm{CaP}$ and $\mathrm{SA}$ and $\mathrm{CaP} / \mathrm{SA}$ composite.

\section{Conclusion}

In conclusion, the addition of SA to $\mathrm{CaP}$ was successful as chemical bonds formed between the two substances as proven through the FTIR and FESEM results. Meanwhile, the thermal analysis results showed that $\mathrm{CaP}$ as the matrix can improve the properties of SA where the degradation temperature for SA increased when it was added to $\mathrm{CaP}$.

\section{Acknowledgement}

This research was financially supported by a Short Termed Grant (STG), Vote number U124. The authors would also like to express their deepest appreciation to theOffice for Research, Innovation, Commercialization and Consultancy Management (ORICC), University Tun Hussein Onn Malaysia and to the Centre for Graduate Studies, UTHM for this research opportunity. 


\section{References}

1. C. VanPutte, J. Regan, A. Russo, Seeley's Essentials of Anatomy and Physiology, Chapter 6. Skeletal System: Bone and Joints (2013)

2. T. M. Keaveny, E. F. M., O. C. Y., Chapter 8: Bone Mechanic. Standard Handbook of Biomedical Engineering and Design, 1-28 (2004)

3. S. Ghozal, Densification and Mechanical Characterization of Pure and Doped Hydroxyapatite, National Institurte of Technology, Rourkela, Degree Thesis (2012)

4. S. Sanchez-Salcedo, D. Arcos and M. Vallet-Regi, Upgrading Calcium Phosphate Scaffolds for Tissue Engineering Application, Key Engineering Materials. 377, 19-42 (2008)

5. C. Zhuo, X. Ye, Y. Fan, L. Ma, Y. Tan, F. Qing, X. Zhang, Biomimetic Fabrication of Three-Level Hierarchical Calcium Phosphate/Collagen/Hydrxyapatite Scaffold for Bone Tissue Engineering, Biofabrication. 6, 035013(2014)

6. L. Biolet, V. Lardot, A. Tricoteaux, A. Leriche, F. Cambier, M. Descamps. Processing and Properties of Calcium Phosphates Bioceramics by Hot Isostatic Pressing,. MATEC Web of Conference. 7, 04020 (2013)

7. J. Hashim, SainsBahan. 1stedidtion. Johor Bahru:UniversitiTeknikal Malaysia (UTM) Press, pp. 212-258

8. G. Turco, E. Marsich, F. Bellomo, S. Semeraro, I. DOnati, F. Brun, M. Grandolfo, A. Accardo, S. Paoletti, Alginate/Hydroxyapatite Biocomposite for Bone Ingrowth: ATrabecular Structure with High and Isotropic Connectivity. Biomacromolecules. 10, 1575-1583 (2009)

9. G. Chen, T. Ushida, T. Tateishi, A Biodegradable Hybrid Sponge Nested with Collagen Microsponges. John Wiley \& Sons, Inc. (2000)

10. M. Rajkumar, N. Meenakshisundaram, V. Rajendran, Development of Nanocomposite based on Hydroxyapatite/Sodium Alginate: Synthesis and Characterization. Materials Characterization. 62, 469-479. (2011)

11. Y. L. Kuen, D. J. Mooney. Alginate: Properties and Biomedical Application. Progress in Polymer Science. 37, 106-126 (2012)

12. M. H. Sheridan L. D. Shea, M. C. Peters, D. J. Mooney, Bioabsorbable Polymer Scaffolds for Tissue Engineering Capable of Sustained Growth Factor Delivery. Journal of Controlled Release. 64, 91-102 (2000)

13. C.C. Ribeiro, C. C. Barrias, M. A. Barbosa, Calcium Phosphate-Alginate Microspheres as Enzyme Deliver Matrices. Biomaterial. 25, $4363-4373$ (2004)

14. I. Mobasherpour, M. S. Heshajin, A. Kazemzadeh, M. Zakeri, Synthesis of Nanocrystalline Hydroxyapatite by using Precipitation Method. Journal of Alloys and Compounds. 430, 330-333 (2007)

15. K. Zhuo, X. Zhang, Z. Chen, L. Shi, W. Li, Preparation and Characterization of Hydroxyapatite-Sodium Alginate Scaffolds by Extrusion Freeforming., Ceramic Internationl. 41, 14029-14034 (2015)

16. Z. Li, H. R. Ramay, K. D. Hauch, D. Xiao, M. Zhang, Chitosan-Alginate Hybrid Scaffold for Bone Tissue Engineering, Biomaterials. 26, 3919-3928 (2005)

17. S. K. Papageorgiou, E. P. Kouvelos, E. P. Favvas, A. A. Sapalidis, G. E. Romanos, F. K. Katsaros, Metal-Carboxylate Interactions in Metal-Alginate Complexes Studied with FTIR Spectroscopy. Carbohydrate Research. 345, 469-473 (2010)

18. I. Rehman, W. Bonfield, Characterization of Hydroxyapatite and Carbonate Apatite by Photo Acoustic FTIR Spectroscopy. Journal of Materials Science: Materials in Medicine. 8, 1-4 (1997) 
19. A. Ślósarczyk, Z. Paszkiewicsz, C. Paluszkiewicz, FTIR and XRD Evaluation of Carbonated Hydroxyapatite Powder Synthesized by Wet Methods. Journal of Molecular Structure. 744-747, 657-661 (2005)

20. L. Berzina-Cimdina, N. Borodajenko, Research of Calcium Phosphate using Fourier Transform Infrared Spectroscopy, Infrared Spectroscopy-Material Science, Engineering and Technology. Pp 123-148 (2012)

21. I. S. Neira, Y. V. Kolen'ko, O. I. Lebedev, G. V. Tendeloo, H. S. Gupta, F. Guitian, Y. Masahiro. An Effective Morphology Control of Hydroxyapatite Crystals via Hydrothermal Synthesis, Crystal Growth and Design. 9, 466-474 (2009)

22. X. Chaobo, L. Yongshang, L. Hongjuan, Z. Lina, Note: Preparation and Physical Properties of Blend Films from Sodium Alginate and Polyacrylamide Solutions. Journal of Macromolecular Science: Pure and Applied Chemistry. A37 (12), 16631675 (2000)

23. A. A. Said, Thermal Decomposition of Some Divalent Metal Alginate Gel Compound, Polymer Degradation and Stability. 39, 393-397 (1993) 